\title{
O PARAEXCITAÇÕES (REIZSCHUTZ) E A PARASKEUÊ
}

Fábio Roberto Rodrigues Belo*

\begin{abstract}
RESUMO. A noção de paraexcitações (Reizschutz), tal como formulada por Freud, tem forte viés biológico. É possível re-escrevê-la, a partir da teoria da sedução generalizada de Jean Laplanche, mostrando sua constituição nas relações originárias com o outro. O exame da literatura sobre a noção mostra claramente a dimensão ética e estética desse conceito. Autores relacionam condutas tais como a anorexia, a toxicomania, a hipocondria e a conduta criminosa como resultado da má constituição do paraexcitações. Nesse sentido, é possível aproximar o conceito da noção grega Paraskeuê, um escudo moral produzido ao longo da vida, tal como foi estudado por Michel Foucault. Conclui-se ser desejável re-escrever o conceito, integrando-o à história das práticas do cuidado de si para salientar os aspectos éticos e estéticos presentes no exercício clínico de reconstrução do paraexcitações.
\end{abstract}

Palavras-chave: Escudo protetor; moral; sofrimento.

\section{THE PROTECTIVE SHIELD AND THE PARASKEUÊ}

\begin{abstract}
The notion of the protective shield (Reizschutz), as formulated by Freud, has a strong biological bias. It is possible to redescribe it through Jean Laplanche's theory of generalized seduction, showing its constitution in the originary relations with the other. The exam of the literature about the notion clearly shows the ethical and esthetical dimensions of this concept. Authors relate conducts such as anorexia, drug addiction, hypochondria and criminal behavior as the results of a poor constitution of the protective shield. In this sense, it is possible to connect this concept to the Greek notion of Paraskeuê, a moral shield produced throughout life, as studied by Michel Foucault. We conclude to be desirable redescribing the concept, integrating it to the history of the care of the self's practices in order to emphasize ethical and esthetical features present in the clinical exercise of reconstructing the protective shield.
\end{abstract}

Key words: Protective shield; moral; suffering.

\section{LA PROTECCÍON CONTRA LAS EXCITACIONES (REIZSCHUTZ) Y LA PARAKEUÊ}

RESUMEN. La noción de protección contra las excitaciones (Reizschutz), tal como fue formulada por Freud, tiene un fuerte sesgo biológico. Es posible redescribirla, desde la teoría de la seducción generalizada de Jean Laplanche, mostrando su constitución en las relaciones originarias con el otro. El examen de la literatura sobre la noción enseña claramente la dimensión ética y estética de este concepto. Autores hacen una conexión de conductas como la anorexia, la toxicomanía, la hipocondría y la conducta criminal como resultado de la mala constitución del protector contra excitaciones. En este sentido, el concepto se asemeja a la noción griega Paraskeuê, un escudo moral producido a lo largo de la vida, como ha estudiado Michel Foucault. Se concluye que es deseable la redescripción del concepto, integrándolo a la historia de las prácticas del cuidado de sí para destacar los aspectos éticos y estéticos presentes en el ejercicio clínico de reconstrucción del protector contra excitaciones.

Palabras-clave: Escudo protector; moral; sufrimiento.

Doutor em Estudos Literários (Literatura Brasileira), pela Universidade Federal de Minas Gerais. Professor Adjunto I, no Departamento de Psicologia, da Universidade Federal de Minas Gerais. 
Freud elabora duas metáforas a fim de explicar como o aparelho psíquico se protege contra os estímulos que vêm do exterior. A primeira metáfora está no capítulo IV de "Além do Princípio do Prazer" (Freud, 1920/1976), no qual ele compara o aparelho psíquico a um organismo vivo cuja superfície vai se modificando, se calcinando de forma a proteger as outras camadas de percepção de um possível excesso de estímulos externos. Essa camada é denominada por Freud de Reizschutz, termo que pode ser traduzido como escudo protetor contra estímulos ou, como sugerem Laplanche e Pontalis (1992), paraexcitações ${ }^{1}$. A segunda metáfora está no artigo "Notas sobre o 'Bloco Mágico"', no qual Freud (1925/2007) compara o aparelho psíquico ao Bloco Mágico, um brinquedo no qual se pode escrever e, ao se levantar sua folha de cobertura, as inscrições ali feitas se apagam. Essa folha de cobertura, argumenta Freud, seria como o paraexcitações: ele também protege as camadas posteriores.

Meu trabalho consiste em analisar esse conceito de Freud - o Reizschutz - comparando-o a uma noção importante na filosofia helenística: a paraskeuê. Michel Foucault (2001), no livro "A Hermenêutica do Sujeito", faz uma análise dessa noção e é a partir dela que farei o presente artigo.

A paraskeuê é uma preparação do indivíduo para que ele se proteja contra os eventos imprevistos. Trata-se de uma armadura constituída ao longo da existência de alguém por meio de exercícios: a escrita, a meditação, o exercício físico e tudo o que foi denominado "cuidado de si" (Foucault, 2001, p. 307). Esse conjunto de práticas visa a deixar o sujeito preparado para enfrentar eventos que poderia denominar, de um ponto de vista psicanalítico, traumáticos. Trata-se de um longo trabalho que visa a transformar o logos em ethos, isto é, os discursos em práticas de vida.

Penso que o paraexcitações não está determinado de uma vez por todas. A partir da teoria da sedução generalizada, proposta por Jean Laplanche, sugiro que os estímulos contra os quais tal engrenagem é montada são sexuais. Nesse sentido, pode-se imaginar que o Reizschutz seja maleável, e não calcinado, como na primeira metáfora de Freud, e nem tão inerte como na metáfora do bloco mágico. Essa maleabilidade depende, evidentemente, do trabalho analítico. De qualquer maneira, parece ser indispensável um sistema

O novo acordo ortográfico muda a forma pára-excitações para essa. Já aqui percebemos como a linguagem, no caso, a ortografia já é um paraexcitações que ajuda a simbolizar diferenças. A ambiguidade da nova forma é interessante: serve para parar, mas serve também para ir em direção às excitações. de proteção como esse proposto por Freud, daí tentar trazer para o campo analítico a noção de paraskeuê.

Reabilitar o conceito de paraexcitações, ainda mais aproximando-o de uma noção da filosofia moral, pode dar margem às críticas que condenam a aproximação da psicanálise a qualquer espécie de psicologia do ego. Responderei a essas críticas na medida em que acredito que a análise é uma prática do cuidado de si. Por mais que se esteja interessado em reconhecer e dar primazia ao inconsciente, não se pode recusar os efeitos de uma análise sobre o eu do paciente. Que esses efeitos estejam sempre entre o logos e o ethos é uma das conclusões que desejo mostrar.

\section{CONTRA O QUE O HUMANO SE DEFENDE?}

Contra quais estímulos os seres humanos se defendem? O humano não se protege apenas contra as intempéries da natureza e também não se protege apenas corporalmente. Pela teoria da sedução generalizada (TSG), compreende-se que, na situação originária, o infante é alvo sexual dos adultos que cuidam dele. Alvo consciente e inconsciente. Excitações sexuais - verbais e não-verbais - são depositadas na criança. Essas excitações funcionam como mensagens. Estas, por sua vez, devem ser traduzidas. Os mesmos adultos que excitam também fornecem material para tradução dessas mensagens. No entanto, essas traduções feitas pelo bebê sempre serão precárias. Primeiro, porque os bebês só aos poucos adquirem material simbólico para elaborar essas excitações; segundo, porque essas mensagens estão comprometidas com o inconsciente dos adultos, isto é, as mensagens são enigmáticas, nunca são completamente claras; terceiro, porque o sentido dessas mensagens só será dado muito tempo depois, $a$ posteriori.

De um lado, o que foi traduzido forma o ego, uma rede sempre em expansão e em busca de sentido, de síntese. Do outro, sendo imperfeitas, as traduções deixam restos. Esses restos podem ser denominados de objetos-fonte da pulsão. É o isso, algo um tanto sem nome e sem sentido, que visa des-ligar, romper, atacar as redes já construídas de sentido. Em termos pulsionais, pode-se ver de um lado a pulsão sexual de vida e de outro a pulsão sexual de morte.

Pela TSG, fica claro que os estímulos contra os quais devemos nos proteger são os sexuais, especialmente aqueles mais difíceis de serem traduzidos, aqueles que colocam mais em risco à rede egoica.

Para Jean Laplanche (1992a), a situação originária de cada um de nós impõe que nos protejamos dos 
estímulos vindos do outro. Não apenas dos estímulos externos, mas daqueles implantados em nós e que permanecem nos atacando desde dentro.

$\mathrm{O}$ eu, em grande medida, pode ser visto como um tipo de escudo. Escudo de si mesmo, por assim dizer. Ele é o resultado das traduções dessas excitações depositadas pelo outro em nós. A questão é que o resto dessas traduções, aquilo que permanece sem ser metabolizado, continua a atacar o eu. É contra esses estímulos internos que o eu luta e se protege. Existem muitas formas de se defender ou de resistir. E essas formas podem e são constantemente julgadas do ponto de vista ético e estético. Acredito que boa parte de uma análise visa a perlaboração desses julgamentos.

\section{METÁFORAS DE FREUD}

Nas duas metáforas utilizadas por Freud, está presente a ideia de que "no sentido do interior, não pode haver esse escudo (...)" (Freud, 1920/1976, p. 44). Como o eu se defenderia, então, desses estímulos vindos de dentro? Para Freud, "há uma tendência a tratá-las [as excitações internas] como se atuassem, não de dentro, mas de fora, de maneira que seja possível colocar o escudo contra estímulos em operação, como meio de defesa contra elas" (Freud, 1920/1976, p. 45). É essa a origem da projeção.

Além da projeção, podemos pensar no contrainvestimento como mecanismo de defesa. Ele não ocorre apenas quando o trauma ocorre; na verdade, o contrainvestimento acontece a todo o momento. Nesse caso, é importante imaginar o escudo voltado para dentro não como uma camada calcinada, mas como uma fonte permanente de energia em direção contrária às excitações mortíferas e desligadas.

Freud defende que "a preparação para a ansiedade e a hipercatexia dos sistemas receptivos constitui a última linha de defesa do escudo contra estímulos" (Freud, 1920/1976, p. 47). O sonho traumático é exemplo notável dessa tentativa de dominar $a$ posteriori as excitações. É fenômeno comum na clínica que devaneios cumpram esse papel. Pensemos no obsessivo que repassa as cenas de conflito tentando se defender melhor ou ter uma melhor resposta do que dera então.

Ao comparar essa primeira metáfora, de 1920, com a próxima, de 1925, perceberemos algumas diferenças (cf. Freud, 1925/2007). A metáfora do bloco mágico retira em grande parte a vitalidade do escudo. Ele é comparado à folha de papel que protege a camada de cera que vem abaixo dela. Ela nada retém. Isso nos parece problemático: não parece possível conceber o sistema Pcpt.-Cs. como não guardando nada do que fora registrado por ele anteriormente. É verdade que também, no outro extremo, ele não pode manter todas as percepções permanentemente, sob o risco de um excesso de registros que impediria qualquer registro posterior.

Uma primeira comparação entre as duas faz aparecer que a primeira metáfora faz do escudo uma vesícula viva que vai morrendo, calcinando-se em prol do restante do organismo. Já na segunda metáfora, o escudo é uma folha, isto é, algo já sem vida desde o início, muito fixo e com uma função extremamente empobrecida, sendo apenas lugar de passagem.

É importante citar, além dessas duas metáforas, uma terceira, também presente no "Além do Princípio do Prazer”, que por meio dela Freud (1976/1920) toma um modelo biológico para falar do Reizschutz. Ele compara o córtex cerebral ao sistema percepçãoconsciência e a caixa craniana ao escudo protetor. Para Laplanche (1992a), essa pseudobiologia só pode ser sinal de outra coisa.

\section{AS ORIGENS DO REIZSCHUTZ}

Nesta seção, veremos como as teorias sobre o paraexcitações remetem a ele uma origem alteritária. Isso só reforça, a meu ver, o caráter moral dessa noção. Nas interpretações que se seguem fica claro como o escudo protetor é também outro nome para as consequências dos encontros originários entre a mãe e o bebê. Quais as marcas por assim dizer calcinadas desses encontros? Quais as possibilidades de fazê-las se mover, modificar-se?

Hélène Parat (2006) defende que no aleitamento e na relação entre a mãe e o bebê de forma generalizada - há dois polos. Por um lado, a mãe desperta o pulsional - na linguagem de Laplanche (1992b), implanta-o. Por outro, é ela também quem deve servir de primeiro paraexcitações. Parat lembra ainda que não é pequeno o risco de um excessivo paraexcitações materno, isto é, um recalcamento intenso do componente erótico do contato entre a mãe e o bebê. Ela sugere que a mãe deva "tolerar a excitação erótica do seu bebê" (Parat, 2006, p. 181), sem recalcá-la, mas apenas inibindo-a parcialmente. Quando falha esse equilíbrio, o sintoma aparece: "A insônia do bebê se inscreve na problemática do fracasso do papel paraexcitante maternal" (Parat, 2006, p. 191). O fracasso do paraexcitações materno equivale, em grande medida, à precariedade dos escudos produzidos pelo bebê.

Em André Green (1990) também encontramos esse aspecto duplo da mãe. Ele aponta que a "loucura materna" (1990, p. 182) deve ser contrabalançada por outros aspectos da relação mãe-bebê. A mãe deve servir de eu auxiliar, de continente e de espelho: 
O amor maternal tem por objetivo, depois de ter favorecido a eclosão da vida pulsional, apenas torná-la tolerável à criança. Potencialmente a mãe oscila sempre entre o excesso de gratificação e de frustração. Todos os dois têm o mesmo efeito: este de provocar uma excitação pulsional que ultrapassa as possibilidades de elaboração do $\mathrm{Eu}$, isto é, a integração das pulsões numa atividade de ligação. (Green, 1990, p. 183).

Portanto, não há oposição, na realização do traumatismo, entre a mãe ausente e a mãe hiperexcitante (cf. Balier, 1988, p. 166): a mãe é ausente no sentido em que não fornece o escudo protetor contra os estímulos que ela mesma endereça ao seu bebê. Laplanche (1998) é bem explícito: “o principal perigo contra o qual a mãe protege [o bebê] é a própria mãe. A mãe boa é uma trincheira contra a mãe má (...) e é a retirada do amor da mãe que consegue desvendar esse poder maléfico da mãe" (p. 342). De maneira ainda mais clara, explica Bleichmar (2011):

Que a mãe seja suficientemente boa não significa que tenha maior capacidade de holding porque pode dar mais, senão que sua maior capacidade de holding está dada pelo modo em que seu próprio entretecido psíquico é capaz de regular as quantidades que faz ingressar no psiquismo do bebê. Nos primeiros tempos, regulando essas excitações; a posteriori, regulando seu próprio discurso. (Bleichmar, 2011, p. 23)

A mãe má, citada por Laplanche (1998), ou a mãe que não contém suas excitações descritas por Bleichmar (2011) é, por exemplo, aquela descrita por Schaeffer (1997/2008), a mãe que faz do seu bebê "elemento essencial de sua economia [libidinal], rouba seu narcisismo em benefício próprio, e satisfaz suas próprias necessidades infantis em detrimento do reconhecimento daquelas de seu bebê"' (p. 237).

O importante, veremos na próxima seção, é perceber que, quando esgotadas as possibilidades de elaboração do pulsional oriundo da situação originária, temos os casos-limite, as psicoses, as drogadições, eventos proporcionalmente radicais à violência do arrombamento - ou talvez da má constituição - do Reizschutz.

A TSG articula, portanto, nossas relações amorosas originárias com a formação de nossa subjetividade. Desejo defender a ideia que tal descrição é bem próxima daquela que podemos fazer advir da teoria política de Foucault. Também para ele (Foucault, 2001), a formação do sujeito - seu assujeitamento - é um processo paradoxal, a partir do qual só podemos ter alguma autonomia sendo subjugados pelo poder, uma sujeição que implica uma dependência radical (cf. Butler, 1997). A formação do sujeito não pode ser completamente pensada sem o recurso paradoxal a um conjunto de constrições fundadoras. $\mathrm{O}$ escudo protetor, na teoria foucaultiana - e também na freudiana, como quero defender - é outro nome para posição moral dentro de um ethos afetivo. Primeiro, sem dúvida, ganhamos tal escudo e só depois poderemos perceber em qual lugar esse escudo nos coloca. Ele é bom o suficiente? Protege contra o quê? Impede a entrada e/ou a saída de quê? É preciso, com Laplanche (1989), perguntar qual é a natureza desse escudo:

De fato, é a violência das excitações externas
que se supõe ter criado, num primeiro tempo,
pelo menos para uma certa camada, a
permeabilidade absoluta; e, num outro
momento - é caso para perguntar realmente
por quê -, essa mesma ação violenta redunda
em impermeabilidade, na formação de uma
camada endurecida, protetora. Qual é então, a
natureza desse paraexcitações? (Laplanche,
1989, p. 201)

Importante ressaltar esse aspecto levantado por Laplanche: nesses encontros precoces, parte do escudo volta-se ao impermeável, outra parte à permeabilidade que torna o convívio possível. Ora, quando Foucault (2001) retoma a noção de paraskeuê, dessa armadura moral, ele também trabalha sobre essa dialética do permeável/impermeável, do calcinado e do flexível. A próxima seção é sobre essas características.

\section{RESSONÂNCIAS ÉTICAS E ESTÉTICAS}

Quando vemos as imagens de armaduras antigas, podemos observar que quase nunca elas são apenas uma crosta, uma superfície de proteção. Aproveita-se o ensejo para o adorno. Não é qualquer proteção, mas alguma que também faz valer o estético, as marcas simbólicas, os valores morais. Armaduras também não devem ser inflexíveis, mas impermeáveis. Não tão fechadas, porém, que impeçam aquele que as utiliza de retirá-las. Perceba que essa metáfora também está sujeita à dialética explicitada acima. Nessa seção, gostaria de apresentar algumas teorias que mostram como o paraexcitações é descrito ética e esteticamente.

Em algumas armaduras estão presentes zoomorfismos (o bico do pássaro, as garras do leão) que denunciam que a casca que conseguimos fazer para nós mesmos não é propriamente parte de nós. As marcas da alteridade em nossas defesas podem ser mais ou menos evidentes. Acredito, todavia, que o 
caráter narcísico do paraexcitações tende a recusar as origens alteritárias desses escudos.

A escolha - consciente e inconsciente - dessas armaduras necessariamente passa pelo ético e pelo estético. Pensemos no obsessivo devidamente resguardado por seus rituais sistemáticos, suas rotinas inflexíveis, sua vida pobre de emoções, absolutamente fechada ao imprevisível. Que essa vida possa ser um modelo de proteção, garantia de segurança, não quer dizer que nossa comunidade moral a acolha como bela, interessante ou ideal. Nem, por outro lado, a vida perversa e sem limites, das drogas e das aventuras radicais e mortíferas, da abertura infinita às contingências, de uma liberdade próxima à loucura. Entre esses extremos, o matiz das defesas, uma dialética permanente sem síntese entre o ético e o estético.

Acompanhemos alguns autores na descrição que fazem, a partir da psicanálise, sobre possíveis escudos protetores. Veremos como eles podem ser mais ou menos feios, mais ou menos eticamente relevantes. Que o leitor repare, desde já, como não estamos lidando com descrições neutras do ponto de vista ético ou estético. Que note também que estamos defendendo a ideia de que as defesas são tão sexuais quanto contra aquilo se erigem. Se o que demanda a defesa é o ataque sexual proveniente do outro, a defesa que será colocada em prática também é sexual, necessariamente atravessada pelas marcas da alteridade - nesse sentido, sempre éticas e estéticas, sempre políticas e moralmente julgadas.

\section{Ética e estética da teoria}

A angústia pode ser vista como uma primeira tentativa de ligação ou de imobilização do afluxo de excitações. É, por assim dizer, um paraexcitações dinâmico: um contrainvestimento ativo bem diferente de modificações no eu permanentes (cf. Laplanche, 1992e, p. 156). A angústia que deveria vir em primeiro lugar a fim de se evitar o trauma pode vir por último caso o trauma aconteça. É o caso dos sonhos traumáticos que têm por finalidade controlar $a$ posteriori a angústia cuja omissão foi a causa da neurose traumática (cf. Laplanche, 1998).

Daniel Widlöcher (2000) propõe que o autoerotismo é uma primeira criação psíquica e funciona como um paraexcitação, e é também "uma maneira de conter as experiências traumáticas e os conflitos arcaicos" (p. 46). Essa leitura está de acordo com Balier (1988), que lembra a importância do autoerotismo para a interiorização/apaziguamento das excitações maternas. É nesse sentido que devemos compreender quando Laplanche (1998) diz que o recalcamento é homólogo à instauração do paraexcitações.
Serge Tisseron (2006) defende que o pudor é um paraexcitações: o pudor defende a criança das excitações que vêm dos pais. Para que as crianças adquiram esse escudo, diz o autor, basta que os pais sejam pudicos com elas de tal forma que interiorizem esse sentimento (cf. Tisseron, 2006).

Gabriel Burloux (2004) elabora uma interessante teoria sobre os hipocondríacos e "lombalgíacos" (p. 60). Segundo o autor, esses pacientes "preferiram a vivência da dor à mortificação do paraexcitações" (p. 61). Com razão, Burloux lembra que o paraexcitações freudiano é, metaforicamente, uma parte do psiquismo que perdeu sua qualidade de vivente. O hipocondríaco investe na dor: desde muito cedo toma para si a violência das excitações e se torna ele mesmo um paraexcitações, não morto, mas insistentemente mortificado (cf. Burloux, 2004). A teoria de Burloux deixa bem clara a plasticidade do escudo, como ele pode ser até mesmo o próprio corpo.

Ao lado dos hipocondríacos, temos as anoréxicas. Muitas delas, relata Vladimir Marinov (2008), se identificam com "animais desprovidos de envelope firme" (p. 142), que têm o corpo mole particularmente exposto às efrações do mundo externo: muitas se veem gordas e flácidas, permanentemente invadidas pelo olhar crítico do outro. A recusa à ingestão de alimentos pode ser vista como uma forma radical e metafórica de se proteger das excitações que vêm de fora. Não comer é a única forma de se proteger do que entra, penetra. A magreza extrema talvez seja uma forma de mostrar um vazio radical: nada pode ser contido por um esqueleto. Dessa forma, fica conjurado o corpo informe e monstruoso devastado por excitações nunca devidamente contidas.

São também importantes as interpretações que articulam as drogas ao paraexcitações. Nelas fica também evidente o caráter ético/estético associado ao conceito, como veremos.

Lesourne (2008) diz que o cigarro muitas vezes tem essa função que a mãe deveria exercer. A mãe protetora, paraexcitações, garantia de conforto, é reencontrada no vício tabagista. Até mesmo a noção de espaço e de tempo oriunda das intermitências da presença/ausência da mãe são substituídas pelo controle do fumante (Lesourne, 2008). Há algo de claramente negativo aqui. Impossível pensar numa clínica psicanalítica que propusesse o cigarro como paraexcitações. A teoria de fundo aqui é que o fumante não confronta a situação de tensão que o reenvia a uma falta (da mãe suficientemente boa, do paraexcitações mais ou menos estável); ele exterioriza, no ato de fumar, essa falta jogando com ela e a remediando: "ele chupa, inspira/expira, controla, destrói, mas mina suas satisfações” (Lesourne, 2008, p. 176). 
Pierre Noaille (2002) também propõe que a experiência toxicomaníaca responde à violência materna. A droga fornece ao sujeito um paraexcitação, uma forma de filtrar "a incandescência das representações incestuosas e dessa forma conter a excitação desestruturante" (Noaille, 2002, p. 104). A droga fornece ao sujeito um aparato de proteção diante dos efeitos da sedução enlouquecedora da mãe.

\section{Escudo da instituição}

François Marty (2007) lembra que as instituições para dependentes químicos demandam a renúncia à satisfação (narcísica) para "consagrar uma parte de seus investimentos pulsionais à relação com o objeto externo, o outro" (p. 109). A tarefa dessas instituições de cuidado é fazer esses pacientes reconhecerem as regras que regem a realidade externa: fazer o princípio da realidade prevalecer sobre o princípio do prazer. Adiante, Marty continua:

Esse modo de funcionamento não deixa de lembrar aquele que se observa entre pacientes psicóticos nos quais a realidade externa é sacrificada em prol da onipotência do mundo interno. $\mathrm{O}$ espaço institucional é então considerado como um anexo do mundo interno e tudo o que é produzido nele, todos os atos produzidos nele só traduzem a violência do afrontamento, no seio do eu, das pulsões que procuram uma via de satisfação sem que o eu do paciente possa interpor um sistema de paraexcitações. (...) Na ausência de um dispositivo institucional (um terceiro) permitindo a análise dessa violência (...), a efração do paraexcitações irá se produzir. (Marty, 2007, p. 109-110).

Claríssimo, portanto, que a instituição de cuidado - e é fácil fazer valer essa lógica para o setting psicanalítico - deverá ser o escudo protetor que falta ao paciente. $\mathrm{Na}$ mesma direção aponta Philippe Bessoles (2005): para ele, os adolescentes criminosos são filhos de mães onipresentes e/ou onipotentes que "criam intrusões sistemáticas e alienantes que coisificam seu bebê" (p. 1036). O crime desses sujeitos seria uma forma de se liberar desse domínio arcaico. Mais uma vez, encontramos a mãe excitante demais, sua função de paraexcitação falha e o adolescente procura conter os assaltos de excitação por meio de seus crimes e das punições advindas deles (cf. Bessoles, 2005).

Claude Balier (1988) também sustenta hipóteses próximas às de Marty e Bessoles quando relata que a prisão pode ser vivida como um paraexcitações com relação à violência agonizante das pulsões: "último recurso contra o mortífero incontrolável" (Balier,
1988, p. 17). Ainda na mesma direção que Marty, Balier (1988) sustenta que será o terapeuta investido como paraexcitações que fornecerá condições necessárias para "a redução da clivagem do Eu e ao aparecimento de uma identificação secundária à imago paterna, que restaura a capacidade sintética do Eu e a solidez de um narcisismo unificante" (p. 204).

$\mathrm{O}$ viés moralista das teorias acima é evidente. Existe um pano de fundo aqui: angústia, autoerotismo, anorexia, pudor, ser tomado pela dor e pela preocupação com doenças, usar drogas, entregar-se ao princípio do prazer, não obedecer às regras sociais, cometer crimes, tudo isso deve ser visto como um sinal de uma desadaptação - ética e estética -, um escudo protetor mal-feito. E é justamente aqui que deveríamos convidar para o diálogo a noção de paraskeuê. Para evitar um moralismo simples e para abrir mais espaço para possíveis diferenças nesses tipos de paraexcitações à primeira vista regredidos e indesejáveis.

\section{O TRABALHO DO ANALISTA}

Se o paraexcitações e o recalcamento não são lugares de transformação, eles contribuem, no entanto, por causa de sua função de proteção, ao exercício e à eficácia dos mecanismos de transformação. Sem eles, o aparelho psíquico correria o risco de ser inundado pelas excitações sejam de origem interna ou externa. (Carels, 2002, p. 1509).

Função de proteção mínima para qualquer possibilidade de transformação: se o objetivo de uma análise é a transformação do sujeito, mínima que seja, no sentido de dar-lhe melhores condições de elaborar suas forças e conflitos pulsionais e sua posição diante do inconsciente, então, é importante que esse equipamento de proteção seja também suficientemente equipado para permitir essas mudanças.

Ora, a paraskeuê é exatamente o conjunto de práticas necessárias para nos permitir ser mais fortes diante do que nos sucede. A comparação proposta por estoicos como Marco Aurélio, Sêneca ou Epicteto é entre a arte da vida e a luta (cf. Foucault, 2001). É preciso se preparar, como o lutador, para o acaso: os perigos (materiais ou morais), os eventos que trazem infelicidade etc.

Importante ressaltar que a paraskeuê não é um quadro teórico ou um amontoado de notações morais. Não é um saber para nos conhecermos melhor, mas para que possamos "agir corretamente face às circunstâncias" (Foucault, 2001, p. 509). Corretamente em que sentido? No sentido de um conjunto de princípios que não pertence apenas ao sujeito. 
Princípios morais mantidos pela e na comunidade moral na qual o sujeito está imerso. Não se trata de adaptação ao social: mas de resposta singular, trabalho sobre si mesmo, tradução particular daquilo que nossas interações morais-afetivas nos propõem. Estar preparado para esses eventos morais - como conduzir o namoro, o quanto trabalhar, como se endereçar ao outro, se devo mentir ou não etc. - não requer um código fixo, imutável, mas um exercício permanente sobre si mesmo. Que uma psicanálise possa ser parte desses exercícios é o que proponho.

$\mathrm{O}$ eu que deve advir desse tipo de exercício analítico não é o eu coeso, senhor de si, mas aquele que se vê como experimento perpétuo (cf. Strenger, 2005). Alguém que consiga se ver como uma obra de arte, como propõe Foucault (2001), na esteira de Nietzsche, é alguém razoavelmente disposto a trocar as descrições que faz de si mesmo por outras. Sob quais critérios? Aqueles dados por sua comunidade moral.

Não há apenas um modo de resistir, muito menos não há apenas um modo de se lidar com a alteridade interna (a pulsão e o inconsciente) e externa (o outro e nossos códigos morais). No entanto, há modos de resistir que não acolhemos na nossa comunidade moral. Os textos examinados acima trazem esses escudos como algo inapropriado, algo feio. Angústia, anorexia, crime, drogadicção, insônia, dores... Qual analista há de acolher tais saídas como dignas? Não devem ser tais escudos precários alvos de perlaboração? Como podemos recusar que a psicanálise é um dispositivo moral imerso numa comunidade moral? Não é melhor admitir isso a fim até mesmo de se controlar e pensar até onde pode ir o julgamento moral da psicanálise e do analista? Defender uma neutralidade ou uma atenção livre de julgamento não seria também uma forma de ser conivente com elaborações que provocam sofrimento?

Se há intervenção no sentido de demover uma anorexia ou de apaziguar um quadro de angústia é porque julgamos que tais posições subjetivas não são interessantes. $\mathrm{O}$ analista não pode ser neutro diante do sofrimento do outro. Isso não quer dizer que ele deva agir como um moralista ou um padre ou um filósofo. O que muda é o modo de intervenção diante do sofrimento alheio. O analista, ao contrário dos padres e filósofos, sabe que o trabalho de mudança não é um trabalho da razão, do convencimento, mas, de trazer à tona o inconsciente, perlaborar afetos, (re)simbolizar vivência. Essa tarefa é um exercício ético:

(...) não creio que a disciplina freudiana seja uma ética, mas sim que existe uma questão ética para a psicanálise, ou, mais precisamente, uma questão ética para o psicanalista. Ela consiste - como em qualquer caso no qual compareça a dimensão ética - em "elaborar uma forma de relação a si que permita ao indivíduo constituir-se como sujeito de uma conduta moral". Para este fim, o psicanalista só pode contar com a própria psicanálise. É ela que pode lhe servir para, na medida do possível, realizar a tarefa ética (...). (Mezan, 1998, p. 210; grifo do autor).

Ética, estética e poética da escuta: triângulo indissociável da prática analítica. Laplanche (1992d) diz que o analista tem, através da escuta, uma função poética de paraexcitações. "Através da perlaboração algo que se faz apenas a dois - algo vem suprir as falhas, os rasgos, as monstruosidades irremediáveis do paraexcitações interno" (Laplanche, 1992b, p. 271). Seriam mesmo irremediáveis? Monstruosos sob quais critérios? Não seria também o caso de se pensar na armadura monstruosa de alguns sintomas, como aquelas que provocam medo e o providencial afastamento do outro? Poética das defesas e de possíveis fazeres com as excitações provenientes do outro: isso sempre será, necessariamente, uma tarefa ética e estética, pois sempre imersa numa comunidade moral.

A interpretação do analista, assim como a mãe na situação originária, tem uma dupla função. Ela é excitante, na medida em que desliga as redes egoicas, provoca rupturas de sentido. Mas ela exerce também uma função de paraexcitação, pois "transmitida pela linguagem, faz pressão por uma secundarização (figurabilidade complexa)" (Roche, 2005, p. 42). Roche (2005) sugere que o analista utilize o aspecto duplo da linguagem em suas interpretações: ao mesmo tempo fusional e separadora, a linguagem articula e distingue, dá o sentido e provoca seu deslizamento.

Duparc (2005) articula bem a formação do paraexcitações e o modo de manejar a transferência do analista. Em muitos casos, o analista deve exercer a função paraexcitante e ajudar o paciente a conter a excitação e a transformá-la. Há pelo menos duas situações a distinguir:

\begin{abstract}
(...) um traumatismo da ordem da sedução ou da separação precoce vai ser contra-investido pela constância do quadro, e da neutralidade vigilante do analista. Ao contrário, o adoecimento numa relação sufocante (...) tornará necessário um encorajamento à livre associação e à transferência, apoiada por interpretações um pouco mais sedutoras, etc. (Duparc, 2005, p. 85).
\end{abstract}

\section{NOVAS METÁFORAS, MAIS ABERTAS}

Atento à condução da análise, tendo em vista hipóteses sobre a constituição do paraexcitações, o 
psicanalista acaba por auxiliar seus pacientes a fabricar novas defesas. Inicialmente, proponho pensar em novas metáforas para essas defesas. Como vimos, as metáforas de Freud estão comprometidas com o fechamento. Minha hipótese aqui: valorizar imagens fálicas e fechadas do escudo, às vezes mortas e calcinadas, pode ser uma forma de desvalorizar o feminino, recusar o papel do masoquismo (como posição originária e como resiliência protetora) e, principalmente, se defender das origens penetradas do eu.

Uma defesa, portanto, algo que permita usar a excitação, mas também algo que conduza o sujeito para a excitação. O mito de Perseu serve ao meu propósito aqui. Perceba como Perseu se vale da métis para degolar a medusa. Ele usa seu escudo como espelho e assim se vê livre da imagem que Freud (1922/1976) interpretou como uma representação da castração.

Mais tarde, ainda usando a astúcia, Perseu fará da cabeça da Medusa uma arma sua. Defender-se da castração, nesse caso, é se apropriar de seus efeitos. Usá-la a seu favor. O paraexcitações deve ter um funcionamento mais dinâmico, com uma capacidade de simbolização mais próxima dos mecanismos préconscientes: no nosso exemplo, um escudo pode ser um espelho, ou o que mais os deslizamentos simbólicos permitirem. Clinicamente, podemos pensar nesse uso da castração a seu favor como um acolhimento de alguma passividade.

Penso nas funções protetoras do masoquismo (cf. Rosenberg, 2003), por exemplo, que obrigam a psicanálise a repensar teórica e clinicamente o modo de operação do paraexcitações. Resiliência é, muitas vezes, melhor do que resistência.

O escudo de Perseu que vale não por sua dureza, mas pela sua reflexividade; as tramas e liames psíquicos que valem não apenas pelo que aprisionam, mas também pelo que deixam passar. Metáforas mais próximas do funcionamento do que Freud denominou processo primário. Pensar nelas talvez ajude o analista a conduzir o tratamento de forma também mais aberta, mais propensa à mudança.

\section{OS ESCUDOS DA TEORIA}

Uma última palavra, breve, sobre os efeitos dessas metáforas sobre a teoria psicanalítica como um todo. O bloco mágico e as membranas calcinadas, metáforas de Freud, podem ser vistas como comprometidas com aquilo que Laplanche (1992c) denomina "movimento ptolomaico" (p. XXXV). São metáforas que tendem a fazer perceber o eu como algo fechado, sólido.
Pensar em metáforas comprometidas com a "revolução copernicana" (Laplanche, 1992c, p. XXXIV), do ponto de vista teórico, nos auxilia a imaginar não apenas no tratamento psíquico do sujeito em análise como um tipo de abertura à alteridade, menos traumática e mais prazerosa. Auxilia também a pensar na própria teoria psicanalítica como mais aberta à diferença, menos ameaçada por ela.

Como espero ter deixado claro, proponho uma abertura da própria psicanálise: ela não pode se ver num tipo de vácuo moral, devidamente protegida ou separada da comunidade moral que a sustenta (e protege!). Pensar numa análise como parte dos muitos exercícios que compõem o cuidado de si é também pensar numa psicanálise mais aberta à interlocução com outras práticas de cuidado ou outras formas de cuidado. Convidar a psicanálise ao diálogo interdisciplinar serve para protegê-la contra o nefasto fechamento narcísico das doutrinas dogmáticas. Nenhuma teoria dentro das ciências humanas está imune a esse fechamento. O antídoto é o diálogo e suas infindáveis traduções entre os parceiros envolvidos.

\section{CONSIDERAÇÕES FINAIS}

A relação entre Foucault e a psicanálise é multifacetada e ainda matéria a ser explorada. Pretendi aqui elaborar apenas uma resposta a uma questão de fundo: a psicanálise é um cuidado de si? Acredito que sim e, nesse sentido, a construção de um escudo moral faz parte do jogo analítico. A análise é um processo de desconstrução e reconstrução de nossos escudos protetores.

Mostrei que os estudos ligados ao paraexcitações têm um forte apelo moral. Geralmente, há uma associação forte entre um escudo frágil e condutas morais inadequadas. Daí, proponho pensar em outras metáforas para esse escudo diferentes daquelas propostas por Freud, a meu ver, muito estáticas e muito desarticuladas da alteridade. Com Laplanche, é possível perceber que o escudo e suas qualidades são provenientes da situação originária. O escudo guarda, portanto, as qualidades morais desse encontro. Nesse sentido, dialogar com a noção de paraskeuê é importante, pois entendo que a psicanálise é um dispositivo de tratamento imerso numa comunidade interpretativa moral ou num campo estratégico de poder e visa à produção de certo tipo de subjetividade. O psicanalista não deve estar desatento ao resultado político-moral atrelado à já árdua tarefa de minoração do sofrimento psíquico. É quanto a esse resultado específico que quis tratar neste texto. 


\section{REFERÊNCIAS}

Balier, C. (1988). Psychanalyse des comportements violents. 6a. ed. Paris: PUF.

Bessoles, P. (2005). Le crime adolescente: criminogenèse et processus adolescens. Adolescence, 54(4), 10211040.

Bleichmar, S. (2011). La construcción del sujeto ético. Buenos Aires: Paidós.

Burloux, G. (2004). La conversion doulourese hystérique. Revue française de psychomatique, 25(1), 53-68.

Butler, J. (1997). The psychic life of power. Stanford: Stanford University Press.

Carels, N. (2002). Limites et transformations psychiques. Revue française de psychanalyse, 66(5), 1497-1536.

Chaves, E. (2011). É a psicanálise um cuidado de si? Mais uma vez... Foucault e a psicanálise. In O. Cláudio. Filosofia, psicanálise e sociedade (pp. 297-306). Rio de Janeiro: Azougue.

Duparc, F. (2005). L'excitation et as mise en cadre. Revue Française de Psychanalyse, jan., 1(LXIX), 75-86.

Foucault, M. (2001). L'herméneutique du sujet: cours au Collège de France -1981-1982. Paris: Gallimard/Seuil.

Freud, S. (1976). A cabeça da Medusa. In J. Strachey (Ed. e J. Salomão, Trad.), Edição Standard Brasileira das obras psicológicas completas de Sigmund Freud. (Volume 18, pp. 329-330). Rio de Janeiro: Imago. (Original publicado em 1922)

Freud, S. (1976). Além do princípio do prazer. In J. Strachey (Ed. e J. Salomão, Trad.), Edição Standard Brasileira das obras psicológicas completas de Sigmund Freud. (Volume 18, pp. 13-85). Rio de Janeiro: Imago. (Original publicado em 1920).

Freud, S. (2007). Uma nota sobre o "Bloco Mágico". In L. A. Hanns (Coord. e Trad.). Escritos sobre a psicologia do inconsciente. (Volume 3, pp. 135-144). Rio de Janeiro: Imago. (Original publicado em 1925).

Green, A. (1990). La folie privée: psychanalyse des caslimites. Paris: Gallimard.

Laplanche, J. (1989). Problemáticas III: a sublimação. (A. Cabral, Trad.). São Paulo: Martins Fontes.

Laplanche, J. (1992a). Novos fundamentos para a psicanálise. (E. Brandão, Trad.). São Paulo: Martins Fontes.

Laplanche, J. (1992b). Implantation, intromission. In J. Laplanche. La révolution copernicienne inachevée. (pp. 355-358). Paris: Aubier.

Laplanche, J. (1992c). Ponctuation: la revolution copernicienne inachevée. In J. Laplanche. La révolution copernicienne inachevée. (pp. III-XXXV). Paris: Aubier.

Laplanche, J. (1992d). Traumatisme, traduction, transfert et autres trans(es). In J. Laplanche. La révolution copernicienne inachevée. (pp. 255-272). Paris: Aubier.

Laplanche, J. (1992e). Une métapsychologie à l'épreuve de l'angoisse. In J. Laplanche. La révolution copernicienne inachevée. (pp. 143-158). Paris: Aubier.

Laplanche, J. (1998). Problemáticas I: a angústia. (A. Cabral, Trad.). São Paulo: Martins Fontes.

Laplanche, J., Pontalis, J-B. (1992). Vocabulário da psicanálise. (P. Tamen, Trad.). São Paulo: Martins Fontes.

Lesourne, O. (2008). Le grand fumeur et as passion. 3a. ed. Paris: PUF.

Marinov, V. (2008). L'anorexie, une étrange violence. Paris: PUF.

Marty, F. (2007). L'instituition de soin: um espace psychique interne. Psychotropes, 1(13), 99-113.

Mezan, R. (1998). O psicanalista como sujeito moral. In R. Mezan. (1998). Tempo de Muda. (pp. 195-210). São Paulo: Companhia das Letras.

Noaille, P. (2002). La toxicomanie comme état limite. In V. Marinov (Org.). Anorexie, addictions et fragilités narcissiques. 2a. ed. Paris: PUF.

Parat, H. (2006). Sein de femme, sein de mère. Paris: PUF.

Roche, R. C. (2005). Excitation de vie, excitation de mort. Revue Française de Psychanalyse, 1(69), 29-44.

Rosenberg, B. (2003). Masoquismo mortífero $e$ masoquismo guardião da vida. (C. Gambini, Trad.). São Paulo: Escuta.

Schaeffer, J. (2008). Le refus du féminin: le Sphinge et son âme en peine. Paris: Quadrige/PUF. (Original publicado em 1997).

Strenger, C. (2005). The designed self: psychoanalysis and contemporary identities. Hillsdale: The Analytic Press.

Tisseron, S. (2006). De la honte qui tue à la honte qui sauve. Le coq-heron, 184(1), 18-31.

Widlöcher, D. (2000). Amour primaire et sexualité infantile: un débat de toujours. In D. Widlöcher. et al. Sexualité infantile et attachement (pp.1-56). Paris: PUF. 